\title{
Subsidio agrario y sociedad rural en Andalucía
}

\section{Simón Pedro Izcara Palacios}

Universidad Autónoma de Tamaulipas

Unidad Académica Multidisciplinaria de Ciencias, Educación y Humanidades

Centro Universitario «Adolfo López Mateos»

A.P.No 476. 87149 CD Victoria, Tamaulipas (México)

sp_izcara@yahoo.com

\section{Resumen}

Las comunidades rurales andaluzas contienen un número desproporcionado de población que está desempleada, subempleada o empleada en ocupaciones temporales de baja retribución salarial. Como consecuencia, se implementaron políticas sociales para sostener a los grupos sociales más vulnerables, además de promover el desarrollo económico de las áreas rurales. Si valoramos la contribución de las mismas a la satisfacción de las necesidades básicas, puede concluirse que los subsidios gubernamentales han sido exitosos en combatir la pobreza. Sin embargo, estos subsidios también han tenido impactos negativos en las áreas rurales. La convergencia de intereses entre trabajadores y empleadores se ha traducido en un extenso fraude. Además, la gente se ha acostumbrado a un sistema que les da un pequeño acceso al consumo, pero que les desincentiva para emprender actividades.

Este artículo, basado en una metodología cualitativa, examina las consecuencias del subsidio agrario, destinado a combatir el problema del desempleo agrario en Andalucía.

Palabras clave: Andalucía, desempleo agrario, subsidio agrario, jornaleros, pobreza.

\section{Abstract}

In Andalusia, rural communities contain a disproportionately high number of people who are either unemployed, underemployed or involved in temporary low-paid occupations. As a result, social welfare policies have been used to sustain the livelihoods of the most vulnerable social groups and to promote economic development of rural communities. If we consider them with respect to the satisfaction of basic human needs, government payments have been successful in combating poverty and deprivation. However, government payments have also generated other pervasive impacts in rural areas. The converging interests of workers and employers have resulted in extensive fraud. Moreover, people have become accustomed to the system, which gives them meagre access to consumption, but discourages them from enterprise.

This paper, towards a qualitative methodology, examines the consequences of the farm subsidy, originally designed to alleviate the farm unemployment problem in Andalusia. Key words: Andalusia, agricultural unemployment, farm subsidy, farm workers, poverty. 


\section{Sumario}

Introducción $\quad$ La exclusión de los jóvenes

Nota metodológica

El problema del desempleo agrario del mercado laboral

en Andalucía

El subsidio agrario

La contracción de la pobreza rural

El acceso desigual al subsidio agrario

La aparición de una cultura de la dependencia

La depreciación del capital humano

El trastocamiento del rol de la mujer jornalera

La reforma de la protección

por desempleo

Conclusión

Bibliografía

\section{Introducción}

En Andalucía, las oportunidades de empleo rural son más escasas que en otras regiones de España (García Sanz, 1999). Históricamente, en las comunidades rurales andaluzas la disparidad en la distribución de rentas ha sido mucho más marcada que en la España septentrional. Los problemas de desempleo, subempleo y pobreza, fruto de una desigual distribución de la tierra, han sido perennes durante casi cinco siglos (Sánchez López, 1980; González, 1989; Moreno Navarro, 1993). Así, los trabajadores asalariados agrarios andaluces han sufrido de forma permanente situaciones dramáticas de pobreza extrema.

Como han señalado Naredo y Sumpsi (1984), esto es la consecuencia del patrón de propiedad de la tierra, el latifundio, y del sistema de organización del trabajo determinado por la Reconquista, definido por los citados autores como «disciplinario», por estar inspirado en los principios jerárquicos de las organizaciones político-militares (autoridad suprema del gran propietario, administrada a través de empleados intermedios con el uso de fuerzas coercitivas).

El medio rural andaluz estuvo constituido, en su mayor parte, por una población empobrecida de jornaleros sin tierras, que vivían bajo la constante amenaza del hambre ${ }^{1}$. Sin embargo, durante siglos, las áreas rurales andaluzas gozaron de una gran estabilidad social. A mediados del siglo XIX, un empeoramiento de las precarias condiciones sociales de los jornaleros, ocasionado por un incremento poblacional, conducirá a una profunda crisis rural, caracterizada por constantes estallidos de descontento popular, que se extienden hasta la Guerra Civil (González, 1989; Moreno Navarro, 1993). La Segunda

1. Yuste Moyano (1991: 210-212) cita la obra de Pablo de Olavide Informe sobre la ley agraria, de 1767, donde los jornaleros agrarios andaluces aparecen descritos como las personas más miserables de Europa, que malviven medio desnudos, durmiendo en el suelo y comiendo pan y gazpacho la temporada que tienen trabajo; y que se encuentran al borde de morir de hambre y viviendo de la caridad durante los largos periodos que carecen de trabajo, bien por sequías, lluvias excesivas, etc. 
República condujo a una mejora de la situación social de los jornaleros agrarios, al mismo tiempo que las organizaciones sindicales agrarias se fortalecieron (Sánchez López, 1980). Durante este periodo, el descontento popular se materializaría en la ocupación de latifundios, lo cual conduciría a una crisis del modelo de organización laboral "disciplinario», imperante desde el siglo XV. Sin embargo, con el inicio del régimen franquista, los grandes propietarios recobrarían su antiguo poder. Como consecuencia, la disciplina laboral sería mantenida a través de una dura represión de todos los movimientos huelguistas, el sindicalismo sería prohibido, y las condiciones sociales de los jornaleros agrarios volverían a deteriorarse (Naredo y Sumpsi, 1984).

Desde finales de los años cincuenta hasta comienzos de los setenta, el crecimiento económico y el incremento de las oportunidades de empleo urbano, mejor remunerado, se traduce en un fuerte éxodo rural y despoblación del campo. La escasez de mano de obra agraria se traduciría en una elevación de los salarios en la agricultura. Esto significaría una mejora de las condiciones de vida de los jornaleros. Así, durante la transición a la democracia, entre 1976 y 1979, los salarios del campo se duplicaron, principalmente como consecuencia del auge del sindicalismo agrario (González, 1989), aunque, paradójicamente, la situación de los trabajadores agrarios comenzó a deteriorarse en este periodo. Durante los años sesenta, el éxodo rural había aliviado el problema agrario. Pero la crisis económica de finales de los años setenta se tradujo en una escasez de oportunidades de empleo en las áreas urbanas; hecho que frena el éxodo rural y conduce a un incremento del desempleo en la agricultura.

Como resultado, la sociedad agraria andaluza presenta un volumen desproporcionadamente alto de personas desempleadas, subempleadas o empleadas en ocupaciones temporales de baja retribución salarial. Por ello, desde comienzos de los años setenta, serían diseñadas políticas sociales destinadas a aliviar las condiciones de vida de los grupos sociales más vulnerables y a promover el desarrollo económico de las comunidades rurales de esta región.

En 1984, como reconocimiento del carácter estructural cobrado por el desempleo agrario, fue introducido un sistema integrado de protección de los trabajadores eventuales agrarios, que tiene como eje central un subsidio por desempleo en favor de los trabajadores eventuales incluidos en el Régimen Especial Agrario de la Seguridad Social (REASS), a quienes se les exige, como requisito para acceder al cobro del subsidio por desempleo, la justificación de sesenta jornadas trabajadas.

Este trabajo de investigación, fundamentado en un acercamiento metodológico cualitativo, parte de la siguiente hipótesis: «el subsidio agrario ha generado en Andalucía una cultura de la dependencia que ha conducido a un incremento de la exclusión social de los jornaleros».

Los objetivos perseguidos son los siguientes:

- Estudiar como ha contribuido el subsidio agrario a combatir la pobreza rural. 
- Analizar el impacto del subsidio agrario en la cultura del trabajo y señas de identidad de los jornaleros andaluces.

- Examinar el efecto que ha tenido el subsidio agrario en la sociedad rural andaluza, particularmente en la mujer y en los jóvenes.

\section{Nota metodológica}

Este trabajo de investigación está fundamentado en una metodología cualitativa. El método cualitativo persigue un análisis en profundidad de un número reducido de casos, con el propósito de explorar determinados procesos o contextos de forma detallada (Wittrock, 1989: 352), de entender la forma en que las personas construyen la realidad social (De Miguel, 1996: 9) y comprender, lo más profundamente posible, un fenómeno vital o una situación determinada (Sierra Bravo, 1994: 25).

La técnica utilizada fue la entrevista en profundidad. Este tipo de entrevista es un diálogo directo y espontáneo (Ortí, 1998: 214) de carácter holístico (Sierra, 1998: 299) entre el entrevistador y el entrevistado, dirigido hacia la comprensión de las perspectivas que tiene el informante respecto de su vida, sus experiencias o sus situaciones (Taylor y Bodgan, 1998: 101).

Un total de 36 trabajadores eventuales agrarios fueron entrevistados en cuatro municipios de cuatro provincias andaluzas: Loja (Granada), Jódar (Jaén), Baena (Córdoba) y El Ejido (Almería). Estas entrevistas fueron realizadas en los meses de julio y diciembre de 2003. Estos cuatro municipios fueron elegidos por ser representativos del jornalerismo andaluz. Jódar fue elegido por ser uno de los municipios agrarios andaluces de mayor tradición de lucha jornalera. Por el contrario, Loja y Baena fueron seleccionados por presentar una tradición reivindicativa más débil. Finalmente, también entrevisté a un jornalero de El Ejido, municipio que representa el paradigma de un nuevo jornalerismo andaluz, dominado por la presencia de jornaleros extranjeros, empleados en la horticultura de exportación en unas condiciones laborales muy desfavorables.

El tipo de muestreo aplicado fue el denominado por Tashakkori y Teddlie (1998: 76) como «stratified nonrandom sampling», o como "stratified purposeful sampling» por Patton (2002: 244). Así, para realizar la selección de la muestra se tuvieron en cuenta dos variables: la edad y el género. Un $50 \%$ de los entrevistados fueron jornaleros de menos de 44 años de edad, y la otra mitad, mayores de 45 años $^{2}$. Por otra parte, un 25\% de los entrevistados fueron mujeres y un $75 \%$ fueron varones ${ }^{3}$ (ver tabla 1 ).

2. Este dato se corresponde con el porcentaje de beneficiarios del subsidio agrario en Andalucía.

3. Este dato se corresponde con el porcentaje de mujeres asalariadas en la agricultura andaluza, de acuerdo con los datos de la Encuesta de Población Activa. Para realizar la segmentación de la muestra en función del género, no utilicé los datos estadísticos de beneficiarios del subsidio agrario, debido a que existe una sobrerrepresentación de la población femenina en estos datos. 
Tabla 1. Códigos utilizados para identificar las entrevistas.

\begin{tabular}{llllllll}
\hline Código & Edad & Género & Municipio & Código & Edad & Género & Municipio \\
\hline E1 & 25 & Varón & Loja & E19 & 26 & Varón & Jódar \\
E2 & 39 & Varón & Loja & E20 & 17 & Varón & Jódar \\
E3 & 62 & Varón & Loja & E21 & 34 & Varón & Jódar \\
E4 & 30 & Mujer & Loja & E22 & 40 & Varón & Jódar \\
E5 & 67 & Varón & Loja & E23 & 29 & Varón & Jódar \\
E6 & 66 & Mujer & Loja & E24 & 48 & Varón & Jódar \\
E7 & 44 & Varón & Loja & E25 & 66 & Mujer & Baena \\
E8 & 43 & Mujer & Loja & E26 & 48 & Varón & Baena \\
E9 & 60 & Varón & Loja & E27 & 42 & Varón & Baena \\
E10 & 52 & Varón & Loja & E28 & 50 & Varón & Baena \\
E11 & 50 & Mujer & Loja & E29 & 45 & Varón & Baena \\
E12 & 49 & Varón & Jódar & E30 & 39 & Varón & Baena \\
E13 & 63 & Varón & Jódar & E31 & 40 & Mujer & Baena \\
E14 & 40 & Mujer & Jódar & E32 & 34 & Varón & Baena \\
E15 & 52 & Varón & Jódar & E33 & 64 & Mujer & Baena \\
E16 & 40 & Varón & Jódar & E34 & 25 & Varón & Baena \\
E17 & 45 & Varón & Jódar & E35 & 28 & Mujer & Baena \\
E18 & 50 & Varón & Jódar & E36 & 42 & Varón & El Ejido \\
\hline
\end{tabular}

Fuente: elaboración propia.

Finalmente, quisiera destacar que el tamaño de la muestra no fue un elemento determinado a priori. Durante el proceso de selección de la muestra, no se buscó una maximización de los números. El acento no recayó en la cantidad de entrevistas realizadas, sino en la riqueza heurística de los discursos recopilados (Padget, 1998: 52). Únicamente cuando se pudo apreciar que se había llegado a un punto de saturación, es decir, a un agotamiento de las ramificaciones del mosaico de diferencias discursivas expresadas por los hablantes, se concluyó que no era necesario incrementar más el tamaño de la muestra.

\section{El problema del desempleo agrario en Andalucía}

En España, el desempleo agrario presenta una distribución geográfica muy desigual. Según los datos de la Encuesta de Población Activa, Andalucía concentraba, en el año 2004, a más de un 33\% de los activos agrarios de España. En cambio, el porcentaje de población ocupada en la agricultura apenas superaba el $27 \%$. Por el contrario, un 70\% del desempleo agrario existente en España aparecía concentrado en esta comunidad autónoma. 
En Andalucía, la introducción de innovaciones tecnológicas y prácticas de gestión que incrementan la productividad del trabajo en la agricultura, han reducido las oportunidades de empleo de los jornaleros. Por otra parte, la ausencia de alternativas de empleo extraagrario ha contribuido a agravar la situación de esta área (Izcara Palacios, 2002a y b). La consecuencia lógica de estos dos procesos ha sido un fuerte incremento del desempleo, hasta el punto de que los términos "trabajador agrario» y "desempleado» llegan a confundirse.

La reducción del empleo agrario en las zonas agrícolas tradicionales, donde predomina una agricultura de secano extensivo, debido a la creciente mecanización de la actividad agraria, es un elemento que está presente de forma constante en las entrevistas. Como consecuencia, el problema de la falta de empleo, la inseguridad laboral y la situación estructural de desempleo que padece esta región son aspectos que aparecen siempre destacados en las entrevistas realizadas a los jornaleros.

\section{El subsidio agrario}

A partir de los años setenta, para paliar el problema del creciente desempleo rural, determinadas medidas, diseñadas para proteger a los desempleados, fueron introducidas en Andalucía; así como en Extremadura. En 1971, apareció el «Empleo Comunitario", un programa que incluía medidas de asistencia social y de promoción del empleo. Aunque, a comienzos de los años ochenta, este programa queda totalmente desbordado. Es por ello que, en 1984, sería introducido un sistema integrado de protección de los trabajadores eventuales agrarios. Este sistema estaría asentado en tres pilares: un subsidio de desempleo, un plan de empleo rural y un plan de formación ocupacional rural. Sin embargo, desde un primer momento, este sistema quedó subordinado al cobro del subsidio de desempleo, que cubriría entre 90 y 300 días anuales y un 75\% del Salario Mínimo Interprofesional, para aquellos trabajadores agrarios eventuales desempleados, que hubiesen cotizado un mínimo de 60 jornadas durante el año en el Régimen Especial Agrario.

El subsidio por desempleo en favor de los trabajadores eventuales incluidos en el Régimen Especial Agrario de la Seguridad Social sufriría diversas modificaciones durante los años noventa. Uno de los aspectos sustanciales de estas modificaciones es la reducción del número de jornadas establecidas como requisito necesario para facilitar el acceso del jornalero al cobro del subsidio por desempleo, para adecuarlas al número de jornadas trabajadas por los trabajadores eventuales agrarios; en el marco de un progresivo estrechamiento de las necesidades laborales en la agricultura (Román Collado, 2004: 149).

Finalmente, el 24 de mayo de 2002, fue aprobado el Real Decreto Ley de reforma de la protección por desempleo y de la ley básica de empleo. Esta reforma garantiza, sin ninguna modificación, los derechos de los trabajadores eventuales que disfrutan del subsidio agrario, pero excluye el acceso a este tipo de protección a quienes lo soliciten por primera vez, o no hayan sido beneficiarios del mismo en alguno de los tres años anteriores a la fecha de realización de la 
solicitud. Por lo tanto, los nuevos empleados del campo quedarán excluidos del sistema y pasarán a integrarse en el sistema contributivo ordinario de la Seguridad Social. Como ha señalado Fernández Domínguez (2003: 105), en la nueva reforma del subsidio por desempleo, continúa vigente el antiguo sistema, pero queda abocado a perder su virtualidad con el transcurso del tiempo. Así, aunque se ha optado por una vía lenta para eliminar el subsidio, éste aparece condenado a desaparecer.

Esta reforma del subsidio agrario desembocó en diez meses de lucha sindical, que se tradujeron en manifestaciones, cortes de carreteras, ocupación de fincas, cierre de las oficinas comarcales del INEM en diversas poblaciones, concentraciones, marchas, paralización de los trabajos en varias fincas, reuniones con el secretario general de empleo y ministros de trabajo, etc. ${ }^{4}$. El resultado de esta actividad reivindicativa fue la introducción de la Renta Agraria para aquellas personas expulsadas del subsidio agrario.

La renta agraria es una ayuda similar al subsidio para trabajadores eventuales agrarios. Sin embargo, éste únicamente se puede solicitar seis veces, y está destinado a aquellos trabajadores agrarios, mayores de dieciséis años, que disponen de cartilla agrícola y han cotizado los doce meses previos a la solicitud de este subsidio, que han residido en Andalucía durante diez años, realizaron un mínimo de treinta y cinco peonadas agrícolas, y, además, no superan un salario mínimo de renta anual. A finales del año 2003, había 173.972 beneficiarios del subsidio agrario, y a finales de marzo del 2004, 6.599 personas eran beneficiarias de la renta agraria en Andalucía ${ }^{5}$. Es decir, la renta agraria supone un porcentaje inferior al $4 \%$ del total de trabajadores eventuales agrarios subsidiados.

\section{La contracción de la pobreza rural}

Pablo Palenzuela (1989), a través del estudio de cuarenta y dos familias jornaleras, realizado en Sevilla en los años 1984 y 1985, calculó la contribución del sistema de protección del desempleo al total de ingresos familiares en un 28\%. Lina Gavira (1992 y 1993), a través del análisis de entrevistas realizadas en 1987 en ocho diferentes áreas andaluzas, estimó la contribución del citado sistema de protección social al total de ingresos familiares en un rango comprendido entre el $18 \%$ y el $37 \%$, con una media del $28 \%$. Si tenemos en cuenta que, a partir de la década de 1990, el problema del desempleo agrario, lejos de disminuir, experimenta un progresivo crecimiento, a la única conclusión que podemos llegar es que la dependencia de las familias jornaleras del subsidio de desempleo sólo puede haberse incrementado. Como afirmaba uno de los jornaleros entrevistados, el subsidio agrario constituye uno de los pilares básicos de la economía doméstica del jornalero.

4. SOC, Boletín especial Tierra y libertad, de marzo de 2003.

5. Diputación de Sevilla. Nota de prensa del 3 de septiembre de 2004. 
[...] dependemos de la aceituna, el subsidio y el espárrago. (E. 24)

El sistema de protección del desempleo implementado a partir de 1984 ha sido exitoso, al eliminar las situaciones de necesidad extrema (Gómez García y Prieto Rodríguez, 2003: 163). Por primera vez en cinco siglos, los jornaleros andaluces disponen de una fuente regular de ingresos. En este sentido, prácticamente todos los jornaleros entrevistados reconocen que el subsidio del campo ha contribuido de forma importante al alivio de la pobreza rural. Cuando se compara la situación actual del jornalero con el pasado, abundan expresiones como: «eran otros tiempos más difíciles» (E. 33). Aunque los jornaleros se siguen definiendo como la clase social más marginal del medio rural andaluz, existe una clara conciencia de que las condiciones de vida de los trabajadores del campo han mejorado en los últimos años, y esta mejora se achaca básicamente al subsidio agrario. Es más, algunos de los entrevistados llegan a argumentar que, si no hubiese sido implementado el subsidio de desempleo, en el medio rural andaluz las situaciones de pobreza extrema se hubiesen multiplicado.

Sin el subsidio, la situación del jornalero hubiese sido catastrófica. (E. 3)

Si no existiera el subsidio agrario, algunos ya hubieran muerto de hambre, seguro. (E. 17)

Por otra parte, el subsidio de desempleo ha frenado el éxodo rural (Hoggart, 1997; Fernández Domínguez, 2003: 107). Como afirmaba uno de los jornaleros entrevistados (E. 26), en ausencia del subsidio agrario la población de los pueblos más pequeños hubiese tenido que emigrar de forma permanente.

\section{El acceso desigual al subsidio agrario}

La extensión del fraude en el cobro del subsidio agrario es un hecho suficientemente documentado. Han sido numerosos los casos de compra-venta de certificaciones de peonadas ficticias (González, 1990; Gavira, 1992 y 1993; Palenzuela, 1993; Romero y Delios, 1997).

En las entrevistas, aparece un claro reconocimiento de la existencia de este fraude en el cobro del subsidio agrario. La actitud de los jornaleros respecto al fraude se debate entre una aceptación del mismo, ya que contribuye a paliar los efectos de la falta de empleo, y una actitud de rechazo. En este sentido, quisiera resaltar el discurso de un jornalero de Loja de sesenta años de edad (E. 9), quien señalaba el hecho de que había mucha gente, principalmente mujeres, que recibían el subsidio agrario sin haber trabajado en la agricultura. Pero, por otra parte, también afirmaba que el problema no era el fraude en el cobro del subsidio; sino, la falta de empleo. Por lo tanto, según este entrevistado, una persona desempleada, sin recursos económicos, estaría en su derecho de cobrar el subsidio, aunque fuese de forma fraudulenta, ya que en el 
fondo este subsidio no sería sino una ayuda económica destinada a los más necesitados del campo andaluz.

Por otra parte, según algunos de los jornaleros entrevistados (E. 5; E. 6; E. 7; E. 10 y E. 11), el hecho de recaer la responsabilidad de certificar las jornadas trabajadas en los empleadores estaría provocando que aquéllos que tienen una mejor relación con éstos tuviesen un mayor acceso al subsidio. Así, señalan como, entre las familias de algunos agricultores, se estarían produciendo alianzas para certificarse jornadas trabajadas entre sí. En este sentido, un agricultor no puede certificar jornadas trabajadas a un miembro de su familia; pero sí puede certificar jornadas trabajadas a familiares de otro agricultor, que a su vez certifica jornadas trabajadas a miembros de la familia del primero.

Como consecuencia, algunos jornaleros sin tierra reprochan que el subsidio de desempleo esté siendo acaparado por aquéllos que menos lo necesitan y que poseen una situación económica más holgada.

$\mathrm{Al}$ que tiene beneficia más que al que no tiene. Eso lo dice todo el mundo. Con quien hablamos, siempre dicen igual, que beneficia más al rico que al pobre. Porque ellos mismos se firman uno a otro y ya tienen su seguro de momento, pero nosotros no. Vamos a pedirles firmas y no nos las dan. (E. 8)

Además, la facultad de las autoridades municipales para contratar a trabajadores eventuales agrarios para la realización de obras de infraestructura, de conservación y desarrollo del patrimonio forestal, etc., que dan la posibilidad, al trabajador agrario, de justificar un número adicional de jornadas trabajadas, ha derivado en prácticas de clientelismo político (Cansino, 2000: 23; 2001: 85; Fernández Domínguez, 2003: 113). En un marco de escasas oportunidades de empleo agrario, la identificación de la autoridad municipal con el elemento que puede dar al jornalero acceso al subsidio, a través de la certificación de las jornadas necesarias para reunir el requisito legal, es muy probable que influya en el comportamiento electoral de los beneficiarios ${ }^{6}$.

Una mujer de sesenta y cuatro años de edad, que había sido jornalera toda su vida, señalaba que todos los trabajadores eventuales de la agricultura no tenían el mismo acceso al empleo rural ofrecido por los ayuntamientos. Así, afirmaba que los únicos que accedían al Plan de Empleo Rural eran: «la gente que está pegada más al ayuntamiento, o familiares de la gente que está a cargo del ayuntamiento« (E. 33).

El Plan de Empleo Rural, creado para racionalizar las inversiones públicas en áreas rurales, paliar el problema ocasionado por un marco de estacionalidad en el empleo y fomentar el empleo permanente entre aquellos grupos con un mayor riesgo de exclusión del mercado de trabajo, ha quedado totalmente subordinado a ayudar a que aquellos jornaleros que no reunieron el número

6. Durante los años noventa, fueron numerosos, y suficientemente conocidos, los procesos judiciales contra alcaldes, debido a la certificación de jornadas de trabajo falsas; con la intención de que la persona que recibía la certificación cobrase el subsidio. 
Tabla 2. Relación entre los beneficiarios del subsidio agrario, la población asalariada agraria y los desempleados agrarios en Andalucía.

\begin{tabular}{lccccc}
\hline Año & $\begin{array}{c}\text { (Beneficiarios/ } \\
\text { asalariados)*100 }\end{array}$ & $\begin{array}{c}\text { (Beneficiarios/ } \\
\text { desempleados)*100 }\end{array}$ & $\begin{array}{l}\text { Año } \\
\text { (Beneficiarios/ } \\
\text { asalariados)*100 }\end{array}$ & $\begin{array}{l}\text { (Beneficiarios/ } \\
\text { desempleados)*100 }\end{array}$ \\
\hline 1984 & 95,4 & 113,6 & 1994 & 151,8 & 136,2 \\
1985 & 75,1 & 97,8 & 1995 & 150,8 & 112,2 \\
1986 & 105,4 & 114,0 & 1996 & 125,4 & 103,0 \\
1987 & 108,6 & 120,1 & 1997 & 105,0 & 98,0 \\
1988 & 113,2 & 141,0 & 1998 & 106,1 & 110,8 \\
1989 & 140,1 & 155,2 & 1999 & 115,2 & 120,1 \\
1990 & 140,5 & 176,7 & 2000 & 116,3 & 125,2 \\
1991 & 114,2 & 146,0 & 2001 & 107,2 & 178,4 \\
1992 & 116,0 & 131,9 & 2002 & 113,5 & 157,7 \\
1993 & 145,4 & 137,8 & 2003 & 101,6 & 143,9 \\
\hline
\end{tabular}

Fuente: INE, Encuesta de Población Activa (varios años). MTAS, Anuario de Estadísticas Laborales y de Asuntos Sociales. Elaboración propia.

de jornadas necesarias que les permiten cobrar el subsidio, puedan completarlas; socavando la posibilidad de crear empleo estable y dando origen al consiguiente clientelismo político (Cansino, 2000 y 2001).

Por otra parte, el efecto llamada generado por el subsidio de desempleo ha brincado además la barrera del colectivo que tradicionalmente ha desempeñado las labores del campo, los jornaleros. Grupos sociales que anteriormente no formaban parte de la mano de obra asalariada agraria (amas de casa, estudiantes, etc.), ahora han pasado a convertirse en jornaleros (González y Gómez, 1997). En este sentido, como se aprecia en la tabla 2, el número de beneficiarios del subsidio agrario en Andalucía sobrepasa con creces, tanto al número de asalariados de la agricultura como al número total de desempleados agrarios.

\section{La aparición de una cultura de la dependencia}

En Andalucía, durante siglos, se fraguó una «cultura del trabajo» que estaba asentada en tres elementos: $a$ ) una identificación emocional y ligazón a la tierra; $b$ ) el orgullo por el trabajo bien hecho, y $c$ ) el trabajo de la tierra como única fuente de legitimación de la propiedad. En esta "cultura del trabajo", residía la especificidad social, integración social y autoestima del colectivo jornalero (Moreno Navarro, 1993) ${ }^{7}$. Sin embargo, desde finales de los años

7. La demanda del reparto estuvo presente en las múltiples revueltas sociales que sacudieron Andalucía desde mediados del siglo XIX, hasta las movilizaciones de jornaleros producidas durante los últimos años del régimen franquista y la transición a la democracia. 
setenta, debido a la acentuación de la vulnerabilidad de los trabajadores agrarios en el mercado de trabajo y su dependencia, cada vez mayor, de las prestaciones sociales, este discurso de protesta ha quedado progresivamente silenciado. Los intereses colectivos están siendo desplazados por intereses de carácter más individualista. Su identidad laboral y social, su conciencia de grupo o clase, impregnada de firmes valores de solidaridad, poco a poco se ha ido resquebrajando. Como consecuencia, el discurso jornalero, además de estar sufriendo una pérdida de identidad, aparece inundado por sentimientos de impotencia, inferioridad y dependencia (González, 1989) ${ }^{8}$. La citada «cultura del trabajo" se ha transformado en una "cultura del subsidio» (Fernández Domínguez, 2003: 113).

El discurso de protesta de los jornaleros, que en el pasado estuvo dominado por la demanda de una equitativa distribución de la tierra, ahora aparece volcado en una demanda de los subsidios estatales. Por ejemplo, el sindicalismo agrario, fuertemente erosionado durante las décadas de 1980 y 1990 (Morales Ruiz, 1997), experimenta una profunda revitalización en el año 2002. Sin embargo, la recuperación del vigor de los sindicatos de jornaleros, lejos de estar anclada, como en el pasado, en una demanda del acceso a la tierra, tiene su origen en una lucha por el derecho del jornalero a ser una clase subsidiada. Cuando el Real Decreto de reforma de la protección por desempleo es aprobado en mayo de 2002 y los jornaleros ven peligrar su situación cuasi permanente de subsidiados, es cuando se produce a una fuerte movilización de los trabajadores eventuales del campo andaluz. Así, el incremento de la movilización jornalera, sobre todo en el año 2002, liderada por organizaciones como el Sindicato de Obreros del Campo, aparece centrada en un discurso reivindicativo del derecho del jornalero a recibir un subsidio cuando está desempleado.

Como señalaba un activista sindical de la Unión de Sindicatos de Trabajadores y Trabajadoras de Andalucía, entrevistado en julio del 2003, en Almería:

La gente se acostumbra a depender del Estado, a no reivindicar, no había necesidad de reivindicar la tierra, y esto ha sido la situación. Ahora se ha cambiado algo cuando han querido quitarlo [...], y ahora han vuelto con el tema de luchar contra la pérdida del subsidio [...]. De hecho, pues, el movimiento jornalero ha sufrido un bajón muy grande a partir de la mitad del ochenta, hasta hace muy poco, y los trabajadores van perdiendo las referencias de las tierras.

El sistema de prestaciones sociales introducido para paliar el problema del desempleo agrario ha generado una cultura de la dependencia. Casi tres décadas de altos niveles de desempleo han conducido a que los trabajadores agrarios andaluces se hayan acostumbrado a un sistema que, sin sacarles del círcu-

8. Aunque, en las zonas donde tradicionalmente ha existido una tradición sindical más arraigada, como es el caso del municipio de Jódar, en Jaén, la demanda del reparto de tierras todavía está presente. 
lo de la pobreza, les permite tener un reducido acceso al consumo. Esto ha creado una atmósfera de marasmo y un desinterés por mejorar su situación socioeconómica a través de la iniciativa privada, la búsqueda de empleo en otros sectores y áreas geográficas más dinámicas, etc. (García e Izcara, 2000).

Hay muy poco trabajo, pero también hay pocos trabajadores. La gente nueva se está haciendo a la vida cómoda. (E. 6)

Como señalaba un jornalero: «voy, trabajo, cobro, y déjame tranquilo ya. Tampoco nadie quiere complicarse la vida ya» (E. 29). Así, me he encontrado con casos de agricultores a tiempo parcial que deliberadamente redujeron su producción agropecuaria para no superar el límite de rentas que les descalificase para poder acceder al subsidio agrario. Como afirmaba un líder sindical del Sindicato de Obreros del Campo, entrevistado en Jódar (Jaén) en julio de 2003:

También hay mucha gente que se ha acostumbrado a cobrar el subsidio, trabajan lo mínimo para cobrar el subsidio.

Este sistema de protección social no sólo está exacerbando el rol periférico de los jornaleros en el nuevo orden agrario emergente (Palenzuela, 1993), sino que, además, está contribuyendo a la creación de un gueto desconectado del mercado de trabajo.

No hay vida en el campo, no hay vida ninguna [...] El campo cada vez está peor; es que cada vez hay más maquinaria y menos peonaje [...] Ahora sí, a descansar todos [...] ese es el trabajo que tenemos. (E. 21)

Tradicionalmente, las familias jornaleras habían dependido enteramente de los ingresos del trabajo. Actualmente, las prestaciones por desempleo agrario son la fuente de ingresos más importante de estas familias (Romero y Delios, 1997). Esto ha transformado sus señas de identidad colectiva y su visión de la vida, ya que, en un corto espacio temporal, han pasado de ser un sector de la sociedad activo y productivo, para convertirse en un grupo social subsidiado y no productivo, que no desempeña un rol ocupacional estable.

Actualmente, en el medio rural andaluz, el objetivo perseguido por el trabajador del campo es cobrar el subsidio. Para el asalariado agrario eventual, ya no tiene sentido trabajar en el campo, si con ello no puede acceder al cobro del subsidio de desempleo. Acceder al subsidio agrario es una meta. Sin embargo, únicamente pueden acceder a esta prestación de carácter asistencial aquéllos que están desempleados. Es por ello que, desde el momento en que el jornalero reúne el número de jornadas trabajadas que le permiten acceder al subsidio de desempleo, éste deja de trabajar. El jornalero no puede arriesgarse a dejar de cobrar el subsidio por tener trabajo. El trabajo es escaso, mientras que el subsidio cubre periodos prolongados. Por lo tanto, lo racional para el 
jornalero no es maximizar el número de días trabajados, sino el número de días subsidiados, ya que el subsidio le proporciona unos ingresos estables, mientras que los ingresos del trabajo son inestables.

Sin embargo, el subsidio agrario aporta al jornalero unos ingresos muy bajos. Como consecuencia, debe aprovechar las oportunidades que tenga de ser empleado. Así, cuando el jornalero está subsidiado, y durante ese periodo, le surge la posibilidad de trabajar, se enfrenta al dilema de no trabajar, trabajar y abandonar el subsidio, o trabajar de forma subrepticia y seguir cobrando el subsidio. En este sentido, la inestabilidad ocupacional del jornalero no sólo emerge de una situación de escasez de empleo, sino también de una necesidad de trabajar a escondidas durante los periodos en los que cobra el subsidio.

Lo que yo también he notado, entonces, es una situación un poco, pero también, inestable, porque está trabajando, está mirando a reunir unos jornales para cobrar el PER; pero luego estás cobrando el PER y no puedes trabajar en otros sitios. Tienes que trabajar a escondidas, la situación es un poco, también de inestabilidad, no es la situación de que tengo un trabajo bueno, tengo un sueldo alto, voy todos los días, no me tengo que esconder de nadie, está bien. (E. 10)

Incluso aquéllos que presentan una actitud más crítica hacia el subsidio agrario, y demandan empleo más que prestaciones asistenciales, que califican como «limosnas», no están dispuestos a desplazarse a otro núcleo poblacional para obtener un empleo estable. En este sentido, se estaría dispuesto a cambiar el subsidio agrario por un empleo estable, siempre y cuando lo obtuviesen dentro del lugar donde residen. A diferencia de las décadas de 1950 y 1960, cuando la población rural andaluza emigró en masa hacia áreas urbanas en busca de mejores oportunidades económicas, actualmente los trabajadores agrarios andaluces ya no aparecen dispuestos a emigrar.

Yo digo una cosa, yo vivo del subsidio, pero a mi me gustaría que quitaran el subsidio y nos dieran a cada uno un trabajo. Nosotros estamos hartos de limosnas. Nosotros lo que queremos es un trabajo digno y estar en nuestra casa y no salirnos a trabajar fuera. (E. 14)

El sistema de protección del desempleo, cuyos objetivos eran crear empleo estable e incrementar la cualificación laboral de los asalariados agrarios, ha quedado reducido a un programa social asistencial, que, lejos de ayudar a los trabajadores agrarios eventuales a salir del círculo de la pobreza y marginación social, ha generado una cultura que está contribuyendo a perpetuarla.

El ejemplo más claro de la citada cultura de dependencia aparece representado en la paradoja que muestra el hecho de que la región española que tiene unas tasas más altas de desempleo agrario (Andalucía) sea, al mismo tiempo, la región donde más permisos de trabajo se han concedido a extranjeros en la agricultura, debido a la falta de mano de obra local para la realización de las tareas agrarias. Al convertirse el mínimo de peonadas necesarias para cobrar 
el subsidio agrario en un criterio para aceptar o rechazar nuevos empleos, los empresarios agrarios se enfrentan a veces a serias dificultades para encontrar mano de obra (Fernández Domínguez, 2003: 114). Así, dentro del contingente de trabajadores extranjeros no comunitarios para 2004, fueron ofertados 17.428 empleos de temporada en la agricultura ${ }^{9}$. Paradójicamente, Andalucía, la comunidad autónoma española que tiene el volumen de paro agrario más elevado, concentró más del $58 \%$ del trabajo de temporada en la agricultura.

\section{La exclusión de los jóvenes del mercado laboral}

El subsidio agrario ha contribuido a retener a muchos jóvenes en el medio rural, subempleados en la agricultura. Sin embargo, los jóvenes, desde el mismo momento en que se incorporan al mercado laboral, aparecen condenados a una especie de «jubilación anticipada» (Izcara Palacios, 2002a y b). Los jóvenes rurales están excluidos socialmente, no por el mero hecho de estar desempleados, sino por carecer de perspectivas de futuro. En este sentido, existe una unanimidad en calificar la situación de los jornaleros jóvenes como incierta. Incluso, los mayores, que suelen quejarse de sus escasos recursos económicos, al compararse con los jóvenes, afirman que la situación de éstos últimos es aún peor.

La situación del joven es peor que la de nosotros, porque no hay trabajo. (E. 13)

Los mayores no creas que trabajan, pero los jóvenes trabajan menos todavía. (E. 14)

El joven que trabaja en el campo como asalariado eventual, no vive en una situación de pobreza, porque el subsidio agrario le proporciona unos ingresos constantes. Sin embargo, el trabajo asalariado agrario genera unos ingresos tan precarios que le imposibilitan independizarse.

El que se independiza es que sale de la agricultura, el que se queda en la agricultura, no se puede independizar. (E. 19)

Los jóvenes los veo sin futuro [...] Mi hijo está aquí, pero trabajando en temporada, horita no es temporada [...] Mi hijo está viviendo conmigo, porque no

9. El contingente es un instrumento de contratación de extranjeros en origen para cubrir la oferta de trabajo no cubierta por el mercado de trabajo nacional. El artículo 39 de la Ley orgánica 4/2000, de 11 de enero, establece la posibilidad de convocatoria de un contingente de trabajadores extranjeros. Este contingente es el resultado de las propuestas de las comisiones provinciales del INEM, teniendo como base las ofertas de los empresarios y las previsiones de puestos que no se pueden cubrir con mano de obra española. Ver la resolución de 29 de diciembre de 2003, por la que se dispone la publicación del Acuerdo del Consejo de Ministros, de 19 de diciembre de 2003, por el que se determina el contingente de trabajadores extranjeros de régimen no comunitario en España para el año 2004 (BOE, $31 / 12 / 2003)$. 
tiene a donde poderse ir [...]. Aquí con que no se diga es que no quiero hacer el trabajo; no es que no quiera trabajar, es que no hay. (E. 25)

Por otra parte, también hay que señalar que, durante dos décadas, los jóvenes han podido permanecer en las áreas rurales de Andalucía en una situación de subempleo. El subsidio agrario, aunque escaso, ha servido para completar sus escasas rentas percibidas como trabajadores asalariados eventuales de la agricultura. Sin embargo, la reforma de la protección por desempleo de mayo del 2002 excluye del subsidio a los nuevos empleados del campo. Esta exclusión de los jóvenes del subsidio agrario, que a la postre también va a excluirlos del mercado laboral agrario, es una fuente de preocupación en la sociedad rural andaluza. En este sentido, una jornalera de Baena de sesenta y cuatro años de edad (E. 33) no veía nada halagüeño el futuro de los jóvenes en el medio rural. Según la opinión de esta entrevistada, los jóvenes hasta ahora habían podido subsistir en el medio rural, en una situación de subempleo permanente, debido a que el subsidio agrario les permitía reunir los ingresos mínimos necesarios para llevar una vida digna. Por lo tanto, en ausencia de estos ingresos, los jóvenes ya no podrían permanecer en el medio rural.

\section{La depreciación del capital humano}

El sistema integrado de protección de los trabajadores eventuales agrarios tiene, como uno de sus pilares, impulsar la cualificación profesional por medio del Plan de Formación Ocupacional Rural. Sin embargo, el Plan de Formación Ocupacional, lejos de conectar a los jóvenes con el mercado de trabajo, únicamente les proporciona una formación escasa, desconectada del mercado laboral, y poco útil para encontrar empleo (Baigorri y otros, 1995: 241 y s.). En este sentido, las personas entrevistadas manifestaron un claro escepticismo respecto a los logros del Plan de Formación Ocupacional Rural.

El sistema de protección social de los trabajadores eventuales agrarios no está contribuyendo a una mayor cualificación de los asalariados agrarios. En un marco de reducción progresiva de las necesidades de trabajo asalariado en la agricultura, y de estancamiento en el número de trabajadores, los jornaleros experimentan una dificultad creciente de ser empleados. Esto hace que tengan que realizar desplazamientos estacionales, que en algunos casos suponen atravesar todo el país en busca del escaso empleo existente, para así reunir el número de jornadas trabajadas que les dan acceso al subsidio agrario.

No puedes estudiar, no puedes seguir estudiando, porque estás aquí tres meses y tres meses allí, y siempre los estudios, la mayoría es que fracasan. (E. 19)

Te los tienes que llevar, y los hijos pierden el rumbo hasta que se acoplan allí. (E. 24)

Como ha destacado Lina Gavira (1992), la movilidad forzada de los trabajadores eventuales significa que las familias tienen que sacar a sus hijos de 
los colegios para no perder la oportunidad de reunir el número de días trabajados necesarios para acceder al subsidio de desempleo. Esto tiene repercusiones muy negativas en la educación de los hijos, descalificándoles y negándoles la oportunidad y los recursos necesarios para competir en el mercado de trabajo $^{10}$. Como comentaba un joven jornalero de Jódar: «el hijo del jornalero sigue con la misma de ser jornalero" (E. 23).

Es más, los exiguos ingresos de los jornaleros provocan que sus hijos raramente inicien estudios superiores. Para un trabajador del campo, dar estudios superiores a un hijo supone un esfuerzo monetario que generalmente desborda su economía. Es por ello que el abandono de los estudios a una edad temprana, para comenzar a trabajar, sea siempre la opción más atractiva, tanto para los padres como para los hijos.

Si no hay trabajo, usted cree que podemos costearle un estudio, no se puede. (E. 15)

Este pueblo tiene muy pocos estudiantes [...] la gente del pueblo deja el estudio para trabajar. (E. 23)

El problema es que los estudiantes; aunque sea con beca. Pero los gastos la beca no los cubre del todo, y son unos gastos que no pueden permitirse las familias de los jornaleros. (E. 33)

Aunque algunas familias jóvenes no se resignan a que sus hijos sean jornaleros. Éstas están dispuestas a sacrificarse para que sus hijos asciendan socialmente a través de la educación. Una mujer de veintiocho años de edad afirmaba que ella era jornalera porque sus padres no pudieron darle estudios. Sin embargo, no quería que sus dos hijas, de dos y cinco años, pasasen por lo que ella había pasado.

Yo pienso que mi hija no pase por lo que yo he pasado en el campo, quiero que mi hija estudie y que saque una carrera, si puedo. (E. 35)

\section{El trastrocamiento del rol de mujer jornalera}

La mujer, debido a su condición de género, tradicionalmente ha venido ocupando, y sigue ocupando, un lugar marginal dentro del colectivo jornalero. Es más, una mujer sólo es empleada en la agricultura si va acompañada por un hombre. En este sentido, si una mujer está sola, es soltera o viuda, sus oportunidades económicas en la agricultura quedan absolutamente mermadas.

La mujer que no tiene hombre no puede ir; creen que la mujer sola no puede trabajar, ni defendernos, que incluso nos defendemos igual que un hombre. (E. 14)

10. De acuerdo con la autora, el bajo nivel de educación y cualificación de los hijos de los trabajadores agrarios significa que el $90 \%$ de los hijos y el $58 \%$ de las hijas de familias de jornaleros continúan siendo trabajadores eventuales agrarios. 
En el campo no la quieren, y trabajan como nosotros o más. Tiene que llevar hombre, y si no lleva hombre, no... (E. 22)

La mujer sola, soltera, una viuda, una divorciada, que no tenga un hombre, no consigue trabajo. (E. 24)

Para la mujer soltera, el único empleo que hay es un empleo fuera de la agricultura [...] Porque a la mujer sola no se le quiere; pues no sé por qué. Será porque tiene menos rendimiento. (E. 33)

Aunque en Andalucía la mujer siempre ha formado parte de la mano de obra asalariada agraria (Prados, 1995), en el discurso de los entrevistados aparece una referencia constante a la idea de que la mujer trabaja cada vez menos en la agricultura. En un mercado de trabajo donde existe una competencia tan elevada por el escaso empelo existente, las oportunidades económicas de la mujer son cada vez más exiguas.

Las mujeres; hay ya pocas mujeres en el campo. (E. 3)

La mujer no sale más que prácticamente en la temporada de aceitunas... Trabaja menos. (E. 26)

Antes se acudía más [...] y ahora la mujer va cada vez menos. Lo de la aceituna ahora está más mecanizado y las mujeres tienen menos oportunidades de trabajo. (E. 28)

Cada vez hay menos mujeres trabajando en la agricultura. Se han ido retirando, o se hacen otras labores. Se sembraba garbanzo, pero, como ya no hay nada. (E. 33)

Los hombres suelen cobrar unos salarios más elevados que la mujer. Sin embargo, la principal diferencia entre varones y mujeres es que las oportunidades laborales de los primeros son mucho más elevadas.

El salario no es tanto la diferencia, sólo que los hombres encuentran más trabajo. (E. 4)

Sin embargo, existe una contradicción entre el discurso de los jornaleros, que hace referencia a una reducción de la participación de la mujer en el trabajo del campo, y los datos proporcionados por las estadísticas oficiales. Según los datos de la Encuesta de Población Activa, hasta mediados de la década de 1980 las mujeres representaban menos de un $10 \%$ de la población asalariada. Sin embargo, a partir de 1984, el porcentaje de mujeres jornaleras ha ido incrementándose de forma progresiva, de modo que, en el año 2003, casi un tercio de los asalariados agrarios eran mujeres. Lo que se ha producido en el seno de las familias jornaleras es un trasvase del escaso empleo existente desde el cabeza de familia y miembros varones de la familia hacia la mujer. Como puede apreciarse en la tabla 3, entre 1976 y 1983, la población asalariada agraria disminuye a una tasa elevada ( $\mathrm{de}-5 \%$ en el caso de los varones y ligeramente 
Tabla 3. Población asalariada agraria en Andalucía (tasas de crecimiento anual).

\begin{tabular}{lccc}
\hline & Total & Varones & Mujeres \\
\hline $1976-1983$ & $-4,83$ & $-4,99$ & $-3,12$ \\
$1984-2003$ & 0,24 & $-1,29$ & 7,11 \\
\hline
\end{tabular}

Fuente: INE, Encuesta de Población Activa (varios años). Elaboración propia.

Tabla 4. Jornadas trabajadas al mes por los beneficiarios del subsidio agrario en Andalucía (media de los años 2001-2003, porcentajes).

\begin{tabular}{lccccc}
\hline & 0 días & De 1 a 7 días & De 8 a 14 días & De 15 a 29 días & 30 o más días \\
\hline Total & 68,9 & 9,1 & 10,4 & 11,1 & 0,4 \\
Varones & 59 & 12,2 & 13 & 15,2 & 0,6 \\
Mujeres & 75,3 & 7,2 & 8,7 & 8,6 & 0,2 \\
\hline
\end{tabular}

Fuente: MTAS, Anuarios de Estadísticas Laborales y de Asuntos Sociales (varios años). Elaboración propia.

superior a $-3 \%$ en las mujeres). Sin embargo, entre 1984 y 2003, mientras los asalariados varones decrecen a una tasa anual superior a $1 \%$, las mujeres jornaleras crecen a una tasa muy elevada, superior al $7 \%$.

Aunque, si pasamos a analizar el número de jornadas trabajadas, el número de días trabajados por los varones es sustancialmente superior al de las mujeres. En la tabla 4, se aprecia como, durante los años 2001 al 2003, un 75\% de las mujeres declararon no haber trabajado ningún día al mes, y únicamente un $17,5 \%$ trabajaron más de siete días al mes. Esto significa que las mujeres, de forma más acentuada que los varones, únicamente trabajan el número preciso de jornadas anuales que les permite tener acceso al cobro del subsidio de desempleo (Román Collado, 2004: 152).

Es más, actualmente existen en Andalucía más mujeres receptoras del subsidio de desempleo agrario que varones. Según los datos de la Encuesta de Población Activa, en el año 2003, las mujeres sumaban algo menos del 32\% de la población asalariada agraria en Andalucía. Sin embargo, ese mismo año, un $61,5 \%$ de los beneficiarios del subsidio agrario eran mujeres. Este dato indica que los ingresos familiares dejan de estar concentrados en el cabeza de familia, para aparecer repartidos de forma equilibrada entre todos los miembros de la unidad familiar, varones y mujeres; ya que, si bien las mujeres siguen teniendo una participación mucho menor en la realización de tareas agrarias, el número de mujeres beneficiarias del subsidio de desempleo excede muy visiblemente al de varones.

El elevado número de mujeres beneficiarias del subsidio de desempleo sólo se explica por la existencia de un fraude en la certificación de las jornadas trabajadas (García Sanz, 2004: 266). Éste es un elemento indicativo de que los empleadores están certificando peonadas ficticias a mujeres, posiblemente a 
cambio de la realización de trabajo gratuito, una reducción salarial o una mayor sumisión del cabeza de familia, que es quien realmente está empleado.

A partir de 1984, cuando, a diferencia del Empleo Comunitario, que estaba restringido al cabeza de familia, el «subsidio de desempleo» se extiende a todos los miembros de la familia, las estrategias familiares se centran en la obtención del «subsidio de desempleo» para el máximo número de miembros de la unidad familiar (Anula y Díaz, 1997). Esto ha provocado que las familias jornaleras hayan hecho el mayor esfuerzo por incorporar a la mujer al mercado de trabajo agrario. Como han señalado diversos autores (Cansino, 2000: 25; Fernández Domínguez, 2003: 113), dentro de un modelo de oferta de trabajo donde la unidad de decisión es la familia, existe un trasvase de jornadas entre la primera renta (cabeza de familia) y la segunda renta (hijo, hija, esposa), mediante la colaboración del empleador, con el objetivo de incrementar el número de miembros preceptores del subsidio agrario y, por lo tanto, las rentas familiares. Esto ha conducido a una mayor participación de la mujer (segunda renta) en el trabajo del campo.

Si estamos cuatro en la casa y son mayores de edad, tienen que trabajar también. (E. 22)

Esto ha contribuido a transformar la posición social de la mujer en el seno de las familias jornaleras. El peso de los ingresos femeninos en la economía familiar ha dejado de ser periférico, para pasar a adquirir un peso similar a los ingresos proporcionados por el varón. Como consecuencia, ha ido permeando una mayor igualdad de género dentro del hogar.

Hay una situación; pues, bueno, no es la situación de antes. Ahora somos iguales, hay más igualdad. (E. 35)

\section{La reforma de la protección por desempleo}

La reforma del sistema de protección del desempleo del año 2002 garantiza los derechos de los trabajadores eventuales que disfrutan del subsidio agrario; sin embargo, excluye del acceso al subsidio a quienes no fueron beneficiarios del mismo los tres años anteriores a la fecha de realización de la solicitud del citado subsidio. Aunque la renta agraria incorpora, durante un periodo de seis años, a aquéllos que cotizaron en el REASS el último año, tienen acreditadas más de trenta y cinco peonadas agrícolas y llevan residiendo más de diez años en Andalucía. Como consecuencia, las nuevas generaciones, y aquéllos que abandonaron temporalmente la actividad agraria para insertarse en otra rama de la economía, quedan excluidos del citado sistema.

En Andalucía, prácticamente todos los jornaleros autóctonos están inscritos en el censo del REASS en situación de alta. Como afirmaba un jornalero de veinticinco años de edad (E. 1), si un jornalero no está dado de alta en el REASS, muy difícilmente encontrará trabajo. 
A partir de 1984, los jornaleros andaluces se inscriben en el REASS, porque estar dado de alta en el REASS les supone una inversión altamente remunerada, con la percepción del subsidio por desempleo. Es más, cuando el hijo de un jornalero cumple dieciséis años, éste se apresura a darle de alta en el REASS, para que pueda acceder al subsidio de desempleo. Estar dado de alta en el REASS no se contempla primeramente como la vía de acceso a una pensión de jubilación en el futuro. Esto se contempla básicamente como una inversión altamente remunerada en el corto plazo. Es por ello que la reforma del sistema de protección del desempleo del año 2002 ha generado en Andalucía un clima de confusión.

Para aquellos jornaleros que quedan excluidos del subsidio agrario, porque no fueron beneficiarios del mismo durante alguno de los tres años anteriores a la fecha de realización de la nueva solicitud del citado subsidio, o lo solicitan por primera vez, estar dados de alta en el REASS ya deja de ser rentable. Además, como afirman los propios jornaleros, son los que menos tienen aquéllos que quedan más fácilmente excluidos del subsidio agrario; cuando segmentos sociales con unos ingresos más elevados y una mejor relación con los empleadores, que en ocasiones acceden a esta prestación asistencial de forma fraudulenta, no quedan excluidos.

Como consecuencia, existe una alta probabilidad de que algunos de los segmentos sociales más desfavorecidos dentro de este colectivo, no únicamente ya no puedan acceder al subsidio agrario, sino que, además, queden excluidos del trabajo asalariado en la agricultura, ya que darse de baja en el REASS en Andalucía equivale literalmente a no encontrar empleo en la agricultura.

En este sentido, es ilustrativo el ejemplo de una mujer de cuarenta y tres años de edad, entrevistada en Loja (Granada) en julio de 2003. Ella era hija de jornaleros sin tierra y llevaba trabajando en la aceituna y el tomate desde la edad de diez años. En el año 2002, dejó el trabajo en la agricultura para hacer una sustitución realizando limpieza en un colegio, donde obtenía unos ingresos más elevados que en el campo. Sin embargo, su situación era temporal. Había trabajado durante un año y pensaba que la contratarían otro año más. Como consecuencia, ya no disfrutaba del subsidio agrario, y para volver a trabajar como jornalera, una actividad que había realizado durante más de treinta años, debería darse de alta en el REASS, pero con la incertidumbre de pasar a integrarse en el sistema contributivo ordinario de la Seguridad Social, algo a lo que no estaba dispuesta.

Por ejemplo, a mí ya no me conviene tener el seguro del campo; mejor ahora estoy en una bolsa de trabajo y cuando se acaba, me pongo otra vez en la cola, ¿y qué hago mientras tanto? (E. 8)

\section{Conclusión}

Las comunidades rurales de Andalucía han experimentado, durante las dos últimas décadas, un crecimiento espectacular del desempleo, que no ha aparecido 
asociado a un incremento de la pobreza. El subsidio agrario ha servido para proporcionar a las familias jornaleras un tímido acceso al consumo; también ha contribuido a reducir la pobreza. Es más, éste ha conducido a un incremento de los ingresos femeninos en las rentas domésticas, y con ello ha permeado una mayor igualdad de género dentro de los hogares. Sin embargo, también ha conducido a un trastrocamiento de las señas de identidad colectiva de los jornaleros y a un resquebrajamiento de las señas de identidad de los jóvenes, condenados a una especie de «jubilación anticipada». Además, ha hecho emerger una cultura de dependencia y ha desincentivado la iniciativa privada.

Aunque el subsidio agrario ha servido para reducir los niveles de pobreza rural, no ha logrado frenar el proceso de exclusión social de los jornaleros. Los conceptos de "pobreza» y «exclusión social» no son inclusivos. La noción de pobreza hace referencia a aspectos distribucionales, a la desigualdad de ingresos en términos estáticos. Sin embargo, el término «exclusión social» es multidimensional y hace referencia a aspectos relacionales (falta de integración económica, ausencia de integración social e interpersonal, etc.). Los jornaleros andaluces no están económicamente integrados, porque carecen de empleo estable, están excluidos del mercado de trabajo y carecen de perspectivas de futuro. Por otra parte, no están integrados socialmente porque su integración social aparecía enraizada en su inclusión en el mercado de trabajo. Más aún, como han señalado Schucksmith y Chapman (1998), la integración social implica un acceso no estigmatizado al estado de bienestar, y para los asalariados agrarios recibir el subsidio de desempleo es una fuente de vergüenza y humillación. Por lo tanto, el subsidio agrario ha contribuido a transformar a los trabajadores del campo en un colectivo desintegrado social y económicamente.

La reforma del subsidio agrario del 2002 ya se está traduciendo en una pérdida de atractivo del trabajo agrario para los jóvenes. Como consecuencia, incentivará la búsqueda de empleo y forzará una movilidad de trabajadores hacia otros sectores y espacios. Sin embargo, si en el futuro la gradual extinción del actual sistema social asistencial pasivo no es sustituida por programas específicos diseñados para incluir en el mercado de trabajo a los grupos sociales más desaventajados, posiblemente se produzca un incremento en los niveles de pobreza.

\section{Bibliografía}

AnUla, C.; DíAz, E. (1997). «Mercado de trabajo y estrategias familiares: el caso de la Andalucía rural». Estudios Regionales, 48,15-40.

BAIGORRI y otros (1995). El paro agrario. Paro, mercado de trabajo, formación ocupacional, temporerismo e inmigración en el campo extremeño. Colección Sociedad y Territorio.

CAnsino Muñoz-RePISO, J. M. (2000). «El subsidio agrario. Principales magnitudes (1984-1999)». Revista Española de Estudios Agrosociales y Pesqueros, 189, 11-28.

- (2001). «El subsidio agrario por desempleo a través de sus cifras en Andalucía (1984-2000)». Revista del Ministerio de Trabajo y Asuntos Sociales, 31, 71-89. 
Miguel, J. M. de (1996). «Autobiografías». Cuadernos Metodológicos, 17. CIS, Madrid. FERnÁNDEZ DomíngueZ, J. J. (2003). «Protección por desempleo de los trabajadores eventuales agrarios». Documentación Laboral, 67 (I), 104-125.

GARCÍA SANZ, B. (1999). La sociedad rural ante el siglo XXI. Madrid: MAPA.

- (2004). La mujer rural ante el reto de la modernización de la sociedad rural. Madrid: Instituto de la Mujer.

García Sanz, B.; IzCARa Palacios, S. P. (2000). «Pluriactividad y diversificación de ingresos en el medio rural español». Sociología del Trabajo, 38, 119-134.

GaVirA, L. (1992). «La segmentación del mercado de trabajo rural en Andalucía: Reflejo de una situación de dependencia». El empleo en España. Madrid: Ministerio de Trabajo y Seguridad Social.

- (1993). Segmentación del mercado de trabajo rural y desarrollo: el caso de Anducía. Madrid: MAPA.

Gómez García, F.; Prieto RodríGuez, M. (2003). «Factores explicativos del diferencial del desempleo andaluz». Revista del Ministerio de Trabajo y Asuntos Sociales, 51.

GONZÁLEZ, J. J. (1989). «El discurso jornalero: Desarticulación de la conciencia de clase y pérdida de identidad». Agricultura y Sociedad, 50, 33-73.

- (1990). «El desempleo rural en Andalucía y Extremadura». Agricultura y Sociedad, 54, 229-265.

GONZÁLEZ, J. J.; GÓMEZ, C. (1997). "Clases agrarias, estrategias familiares y mercados de trabajo». En: GÓMEZ, C.; GonZÁLEZ, J. J. (coords.). Agricultura y sociedad en la España contemporánea. Madrid: CIS, p. 565-580.

HogGaRT, K. (1997). «Rural Migration and Counterurbanization in the European Periphery: The case of Andalucía». Sociologia Ruralis, 37 (1), 134-153.

IzCARA PalaCios, S. P. (2002a). «Infraclases rurales: Procesos emergentes de exclusión social en España». Revista Española de Investigaciones Sociológicas, 97.

- (2002b). "Jornaleros desocupados e inmigrantes sobreexplotados: Las nuevas infraclases rurales». En: GÓMEZ, C.; GONZÁLEZ, J. J. (coordinadores). Agricultura y Sociedad el cambio de siglo. Madrid: McGraw Hill.

Morales Ruiz, R. (1997). «Desarrollo y transformaciones históricas en el Sindicato de Obreros del Campo (1976-1994)». Sociología del Trabajo, 32, 31-52

MorenO NAVARRO, I. (1993). «Cultura del trabajo e ideología: El movimiento campesino anarquista andaluz». En: SEvilla GuZMÁN, E.; GONZÁleZ DE MOLINA, M. (eds.). Ecología, campesinado e historia. Madrid: La Piqueta, p. 335-356.

NAREDO, J. M.; SUMPSI, J. M. (1984). «Evolución y características de los modelos disciplinarios del trabajo agrario en las zonas de gran propiedad». Agricultura y Sociedad, $33,45-86$.

ORTí, A. (1998). «La apertura y el enfoque cualitativo o estructural: La entrevista abierta semidirectiva y la discusión de grupo». En: GARCíA FERRANDO, M. A.; IbÁN̂́EZ, J.; ALVIRA, F. (comps.). El análisis de la realidad social. Métodos y técnicas de investigación. Madrid: Alianza Universidad Textos.

PADGET, D. K. (1998). Qualitative Methods in Social Work Research. Challenges and Rewards. SAGE: Thousand Oaks. CA.

Palenzuela Chamorro, P. (1989). «Estrategias económicas domésticas de los jornaleros andaluces: salario, subsidio y economía sumergida». Agricultura y Sociedad, 50, 75-107.

- (1993). "Antropología económica del campesinado andaluz". En: SEvilla GuZMÁn, E.; GonZÁlez de Molina, M. (Editores), Ecología, Campesinado e Historia. Madrid: La Piqueta, p. 357-374. 
PATTON, M. Q. (2002). Qualitative Research and Evaluation Methods. SAGE: Thousand Oaks, CA.

Prados, M. J. (1995). «Temporeras y trabajo en las explotaciones freseras de la costa oriental de Huelva». El Campo, 133, 203-219.

Román COLlado, R. (2004). «Cambios en el perfil del beneficiario del subsidio agrario (1984-2001)». Revista del Ministerio de Trabajo y Asuntos Sociales, 51, 139-155.

Romero, J.; Delios, E. (1997). «La pobreza rural en España». En: Gómez, C.; GONZÁLEZ, J. J. (coordinadores). Agricultura y sociedad en la España contemporánea. Madrid: CIS, p. 581-614.

SÁNCHEZ LOPEZ, A. J. (1980). «La eventualidad, rasgo básico del trabajo en una economía subordinada: El caso del campo andaluz». Sociología del Trabajo, 3/4, 97-128.

ShuCKSMith, M.; Chapman, P. (1998). «Rural Development and Social Exclusion». Sociologia Ruralis, 38 (2), 225-242.

Sierra BraVo, R. (1994). Técnicas de investigación social. Teoría y ejercicios. Madrid: Editorial Paraninfo.

SIERRA, F. (1998). «Función y sentido de la entrevista cualitativa en la investigación social». En: GALINDO CÁCERES, J. (coordinador). Técnicas de investigación en sociedad, cultura y comunicación. México: Pearson Education, p. 275-345.

TASHAKKORI, A.; TEDDlie, C. (1998). Mixed methodology. Combining Qualitative and Quantitative Approaches. SAGE: Thousand Oaks, CA.

TAYLOR, S. J.; BODGAN, R. (1998). Introducción a los métodos cualitativos de investigación. Barcelona: Piadós Básica.

WitTrock, M. C. (1989). La investigación de la enseñanza II. Métodos cualitativos y de observación. Barcelona: Paidós Educador.

Yuste Moyano, R. (1991). «Jornaleros andaluces: El Plan de Empleo Rural ¿¿Solución o problema?». Revista de Fomento Social, 182, 225-242. 